\title{
Changes of Lignin Molecular Structures in a Modification of Kraft Lignin Using Acid Catalyst
}

\author{
Sunghoon Kim ${ }^{1}$, Seungtaek $\mathrm{Oh}^{2}{ }^{2}$ Jungmin Lee ${ }^{3}$, Hyun-gyoo Roh ${ }^{3}$ and Jongshin Park ${ }^{3, *}$ \\ 1 Ore Co. Ltd., Seoul 04781, Korea; bv206driver@snu.ac.kr \\ 2 Hyosung, R\&D Business Labs, Anyang 431-080, Korea; ost@hyosung.com \\ 3 Department of Biosystems \& Biomaterials Science and Engineering, \\ Research Institute of Agriculture and Life Sciences, Seoul National University, Seoul 151-742, Korea; \\ archon04@snu.ac.kr (J.L.); ssangno@snu.ac.kr (H.R.) \\ * Correspondence: jongshin@snu.ac.kr; Tel.: +82-2-880-4628
}

Academic Editor: Volker Altstädt

Received: 31 May 2016; Accepted: 2 August 2016; Published: 5 August 2016

\begin{abstract}
The purpose of this study is to modify lignin for better blending with general purpose synthetic polymers. The possible advantages by using this modification would be cost reduction, better physical properties, and biodegradability. In this study, butyrolactone-modified lignin (BLL) and tetrahydrofuran-modified lignin (THFL) were used for aliphatic chain modification of lignin using an acid-catalyzed esterification method in order to mimic the relation of lignin-carbohydrate-complex (LCC) and cellulose. The results of several analyses indicated that lignin was well modified. It was confirmed that the lignin was modified as expected and the reaction sites of the modification, as well as the reaction behaviors, were varied by the reagent types. The result of $X$-ray diffraction analysis (XRD) analysis indicated that modified lignin/polymer blends increased the crystallinity due to their good compatibility. It can be confirmed that the type of alkyl chain and the miscibility gap between the alkyl chain-matrix affected the mechanical properties enormously in the fungi-degradable environment. From this study, a new method of lignin modification is proposed, and it is found that modified lignin retains the property of the substituted aliphatic chain well. This method could be a proper lignin modification method.
\end{abstract}

Keywords: soft wood kraft lignin; lignin-carbohydrate-complex (LCC); aliphatic chain modification; polymer blend; biodegradability; compatibility

\section{Introduction}

After the "Bronze Age", modern society has evolved into the "Plastic Age". There are many types and properties of plastics, for multiple purposes. Almost every plastic is difficult to degrade, requiring a long time, and causing environmental harm. Thus, raw plastic material from natural resources, without any environment problems, is necessary. In modern times, new plastic research or inventions focus on raw materials which are biodegradable or originated from nature. Therefore, it is necessary to find another natural resource, which is not used as food, have enough amount for industrial applications, and rarely or never used before and lignin may be a good candidate.

Wood is composed of three components; cellulose, hemicellulose, and lignin mixtures, which is called the 'lignin-carbohydrate-complex' (LCC) at the micro-scale. The purpose of any kind of pulping process is to breakup this LCC and use only cellulose [1]. Cellulose, hemicellulose, and every kind of materials which is extracted from wood are used, but not lignin. Kraft lignin is extracted from solution because it cannot be treated the way it is. Specifically, kraft lignin is treated with solutions containing high concentrations of alkali ions and neutralized by a strong acid to create a powder phase mixture which is composed of mostly lignin. Generally, this powder is burnt to supply the 
energy requirement of the production process [2]. Different from the kraft lignin which most of the materials are incinerated, lignosulfonate, organosolv lignin, and other lignins are used as feed binders, adhesives, emulsifiers, etc. However, all of these lignins are hard to use as wide-use materials, like synthetic polymers, due to its unique molecular structure and properties [3].

Many researchers have reported that it is possible to produce thermoplastic materials which contain a large amount of lignin [4]. However, the elongation of such materials tends to decrease dramatically with increasing lignin content in fact, the physical properties of thermoplastic blends are significantly degraded when more than $10 \% \sim 25 \%$ of lignin is incorporated into synthetic polymers, as shown in Figure 1 [5-8]. Therefore, maximizing the amount of lignin in thermoplastic materials while minimizing the corresponding degradation of mechanical properties is a very important research topic. The development of materials with such properties could reduce the price of production and environmental pollution.

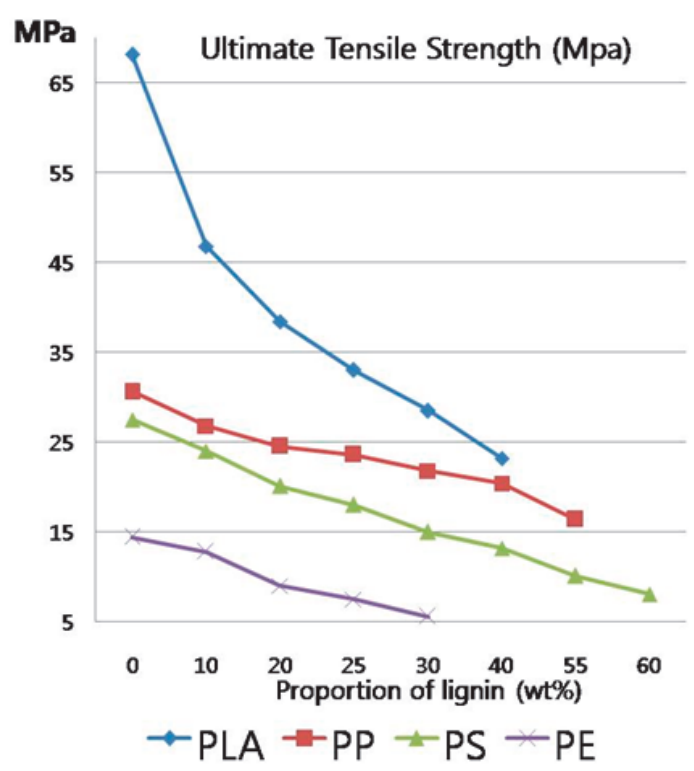

(a)

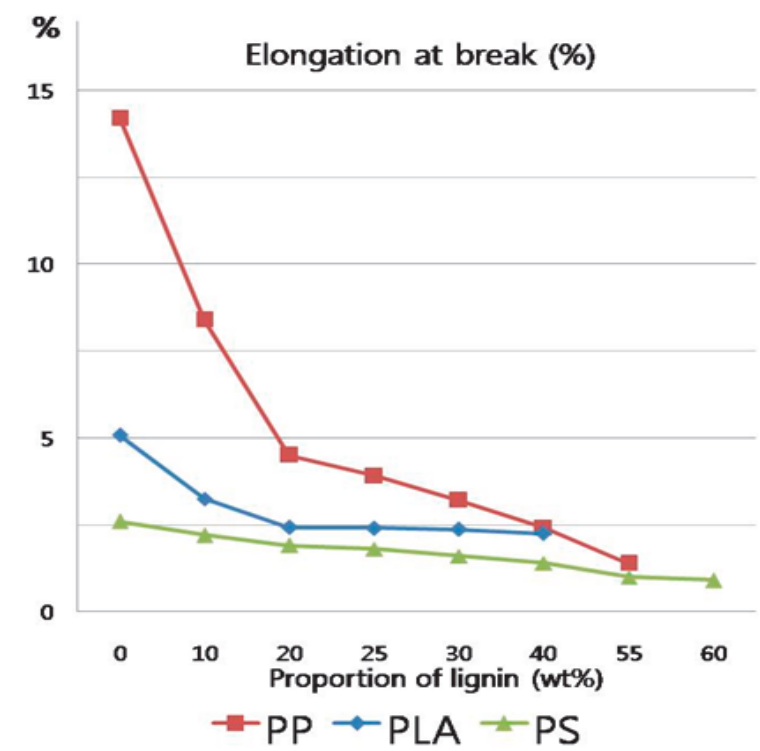

(b)

Figure 1. Tensile properties of lignin-various polymer blends. (a) Tensile Strength and (b) breaking strain [5-8].

Chemical modification of lignin is a major issue in the area of lignin research. Chemical modification of lignin is performed to replace the carboxyl group and hydroxyl group of the lignin by alkylation, acylation, and hydroxyalkylation [9]. A new method is proposed in this study where the lignin functional group is replaced by the proper molecular weight of an aliphatic chain. Replacing a lignin functional group is similar to another lignin modification method like alkylation and/or acylation, but the limitation of these methods is that those with molecular weight which are lower than one hundred Dalton can be substituted. The modification method used in this study faced difficulty in dramatically increasing compatibility between matrixes.

\section{Experimental}

\subsection{Materials}

Tetrahydrofuran and $\gamma$-butyrolactone were used in this study. These reagents and sulfuric acid which were used as catalysts were purchased from Junsei Co., Tokyo, Japan, GR grade. The Indulin $\mathrm{AT}^{\circledR}$ (pine kraft lignin) used in this study was purchased from MeadWestVaco Co., North Charleston, SC, USA. Ingeo ${ }^{\mathrm{TM}}$. Polyethylene terephthalate (PET) $(\mathrm{Mw}=44,650, \mathrm{Mn}=23,410, \mathrm{PDI}=1.91)$ with a low melting temperature-in order to blend with $\gamma$-butyrolactone modified lignin (BLL), polypropylene 
$(\mathrm{PP})(\mathrm{Mw}=210,000, \mathrm{Mn}=49,400, \mathrm{PDI}=4.25)$ —in order to blend with tetrahydrofuran-modified lignin (THFL), were industrial grades and used as they were received. Sabouraud dextrose agar (model No: 210950) purchased from Becton and Dickinson Difco Co., Ltd. (Franklin Lakes, NJ, USA) (BD Difco) was used as a medium and Aspergillus awamori fungus (ATCC 6970) from the Korean Collection for Type Cultures (KCTC) (Daejeon, Korea) and were used for the degradation test.

\subsection{Preparation of Modified Lignin}

A modification procedure was started using fixed $5 \mathrm{~mL}$ reagent and $0.5 \mathrm{~g} 2.5 \mathrm{~g}$ of lignin, according to the $0.5 \mathrm{~g}$ variation, with charge ratio from 10:1 to 10:5. The reaction started with sulfuric acid as a catalyst and was put into a $1 \mathrm{wt} \%$ lignin/reagent mixture. BLL was reacted at $200{ }^{\circ} \mathrm{C}$ in the first half reaction time. After that, the temperature was increased to $250{ }^{\circ} \mathrm{C}$ and reacted for another half reaction time. The THFL was reacted first at $100{ }^{\circ} \mathrm{C}$, and then reacted at $150{ }^{\circ} \mathrm{C}$, like BLL. Agitation speed was $900 \mathrm{rpm}$ for the entire process. The time variations were 10, 20, $30 \mathrm{~min}, 1 \mathrm{~h}, 1 \mathrm{~h}$ and $30 \mathrm{~min}$, and $2 \mathrm{~h}$, respectively, under evaporation in order to remove the byproduct and volatilized reagent. During the two hours of reaction, the viscosity of the mixture was increased rapidly in the last stage.

After following the determined time procedure, the reacted sample was washed with excess distilled water. The modified lignin sinking occurred due to its insolubility and higher density than the distilled water. A small amount of unreacted reagent, unreacted lignin, and catalyst were present as a suspended solid in the supernatant. After sinking, the supernatant was removed and unreacted material suspended to separate from modified lignin. The washed sample needed to be dried under vacuum conditions for use. In order to prevent a side reaction or post reaction due to the minimum quantity of remaining catalyst or reagent when the drying temperature is more than $100{ }^{\circ} \mathrm{C}, 12 \mathrm{~h}$ of vacuum drying must be proceeded at $80^{\circ} \mathrm{C}$ with $30 \mathrm{in.} \mathrm{hg}$, or 762 torr of pressure. To dry the sample completely, it was mixed in $3 \mathrm{~h}$ intervals.

Figure 2 shows a modification time and reaction ratio variation. 10: $\mathrm{X}$ is the fixed reagent ratio versus lignin ratio, time is the whole reaction time of the sample. I.M. means 'impossible mission' due to too many unreacted materials. 31P-NMR analysis was performed on 30-min and one-hour reacted samples (red marked) and FT-IR analysis and solubility tests were performed on all samples.

\begin{tabular}{|c|c|c|c|c|c|}
\hline BLL & 10:5 & $10: 4$ & $10: 3$ & 10:2 & $10: 1$ \\
\hline $10 \mathrm{~m}$ & O & I.M. & I.M. & I.M. & I.M. \\
\hline $20 \mathrm{~m}$ & O & I.M. & I.M. & I.M. & I.M. \\
\hline $30 \mathrm{~m}$ & O & 0 & 0 & 0 & 0 \\
\hline $1 \mathrm{~h}$ & O & O & 0 & O & O \\
\hline $1 \mathrm{~h} 30 \mathrm{~m}$ & O & & & & \\
\hline $2 \mathrm{~h}$ & O & & & & \\
\hline THFL & 10:5 & $10: 4$ & 10:3 & $10: 2$ & 10:1 \\
\hline $10 \mathrm{~m}$ & O & I.M. & I.M. & I.M. & I.M. \\
\hline $20 \mathrm{~m}$ & 0 & I.M. & I.M. & I.M. & I.M. \\
\hline $30 \mathrm{~m}$ & 0 & 0 & 0 & O & O \\
\hline $1 \mathrm{~h}$ & 0 & 0 & O & O & 0 \\
\hline $1 \mathrm{~h} 30 \mathrm{~m}$ & O & & & & \\
\hline $2 \mathrm{~h}$ & 0 & & & & \\
\hline
\end{tabular}

Figure 2. Prepared sample for analysis. 


\subsection{Analyses of Modified Lignin Functional Group Using 31P-NMR and FT-IR}

Thirty-minute modified lignin and one-hour modified lignin were monitored and analyzed by quantitative 31P-NMR using published procedures. NMR spectra were acquired using an AVANCE 600 (Bruker, Karlsruhe, Germany), $600 \mathrm{MHz}$ spectrometer equipped with a quad probe dedicated to $1 \mathrm{H}, 15 \mathrm{~N}, 19 \mathrm{~F}$, and 31P-NMR acquisition. To investigate the functional group change of modified lignin that have different reaction charge ratios and times, solid-state FT-IR spectra for the samples that have the fixed charge ratio, and time variations which were $10 \mathrm{~min}, 20 \mathrm{~min}, 30 \mathrm{~min}$, one hour, and one hour and $30 \mathrm{~min}$, respectively, were obtained with an FT-IR spectrophotometer (Nicolet Is 5, Thermo Scientific Inc., Waltham, MA, USA).

\subsection{Analyses of Modified Lignin in Order to Investigate the Changes of Lignin Contents and Solubility}

In order to investigate the solubility change of modified lignins that have different reaction charge ratios and times, lignin and modified lignin were dissolved in THF, which did not dissolve lignin. Each sample was dissolved in THF with a total concentration of $2 \%,(w / v, 100 \mathrm{mg} / 5 \mathrm{~mL})$ for $5 \mathrm{~min}$ and, after that, they were centrifuged for $5 \mathrm{~min}$ at $1000 \mathrm{rpm}$. After removing the supernatant, surplus THF were volatilized in a vacuum chamber. Residues were weighed to quantify the insoluble fraction of modified lignin. The elemental contents of lignin and $2 \mathrm{~h}$ modified lignin were analyzed using a Thermo Electron Co., Waltham, MA, USA, Flash EA 1112-Elemental $(\mathrm{C}, \mathrm{N}, \mathrm{S})$ Analyzer. Synthetic polymers and minerals, like sand or mineral salts, can be measured without error, although only with a few mg samples. However, natural materials like lignin or animal protein are difficult to measure without any error because they do not have regular empirical formulae. Therefore, lignin and modified lignin were weighed to more than $10 \mathrm{mg}$ before measuring in order to reduce the error. Since the reacted reagent is composed of only carbon, oxygen, and hydrogen, and nitrogen only exists in lignin, the elemental analysis was conducted in order to compare the nitrogen content.

\subsection{Blending of Modified Lignin and Synthetic Polymers}

Modified lignin was mixed with synthetic polymers in proportions of $0,25.0$, and $50.0 \mathrm{wt} \%$ of lignin content. The mixtures were melt blended using a table-type kneader (PBV-0.3, Irie Shokai Co., Tokyo, Japan) at $170 \pm 2{ }^{\circ} \mathrm{C}$ for $20 \mathrm{~min}$. Subsequently, the modified lignin/synthetic polymer composites were compression molded using a two-post manual hydraulic press (\#2699, Carver Inc., Wabash, IN, USA) at $170 \pm 1{ }^{\circ} \mathrm{C}$ and $6.89 \mathrm{MPa}$ for $5 \mathrm{~min}$. The molds were quenched after molding, and then polymer composite sheets were obtained.

\subsection{Tensile Test}

A universal testing machine (LRX Plus, LLOYD Instruments Inc., Bognor Regis, UK) was used to determine the tensile properties of the modified lignin/synthetic polymer composites and its degraded sample. Tensile tests were performed according to the guidelines of ASTM D638. The range of sample thickness was 1.2 to $1.8 \mathrm{~mm}$, and the strain rate was $10 \mathrm{~mm} / \mathrm{min}$. The data are expressed with the averages of a minimum of 10 specimens.

\subsection{X-ray Diffraction Analysis (XRD)}

X-ray diffraction analysis was used to investigate the change of crystalline area by the modified lignin/matrix ratio (D8-discover with GADDS, Bruker, Germany). Basically, the determination is based on the relative intensity of specific peaks. The XRD method has been previously used to study the polymer structures and directly determine the crystallinity of polymers [10]. The determination of the degree of crystallinity thus involves the separation of the peaks scattered by the amorphous phase and the peak reflected by the crystalline phase. The degree of crystallinity can be computed using the equation:

$$
\mathrm{X} c=\frac{I c}{I c+I A} \times 100 \%
$$


where IC and IA are the scattered intensity for the crystalline and the amorphous phase, and XC is the degree of crystallinity of the blend. The degree of crystallinity was calculated by computerized integration values, using baseline integration software (Proteum 2, Bruker, Karlsruhe, Germany).

\subsection{Degradation Test of Blends}

The medium was prepared on the basis of the BD Difco's manual [11] and was sterilized in an autoclave. Subsequently, both sides of a Petri dish $(90 \mathrm{~mm} \times 15 \mathrm{~mm})$ were coated with $15 \mathrm{~mL}$ of medium, and the fungi were seeded. At a temperature of $25^{\circ} \mathrm{C}$ and $80 \% \mathrm{RH}$ (relative humidity), the fungi were grown for $96 \mathrm{~h}$. Afterwards, the blend of $75 \%$ polymer and $25 \%$ modified lignin was placed on the middle of the medium coated surfaces (number of samples $=5$ ). Fungi were allowed to degrade the sample for four weeks, eight weeks, and 12 weeks (Figure 3), and the samples were washed in soapy water for $30 \mathrm{~min}$, then washed in distilled water for $30 \mathrm{~min}$. The washed sample was stored in a desiccator for $24 \mathrm{~h}$ to remove the residual water. Finally, the change of the sample weight and mechanical properties were measured.

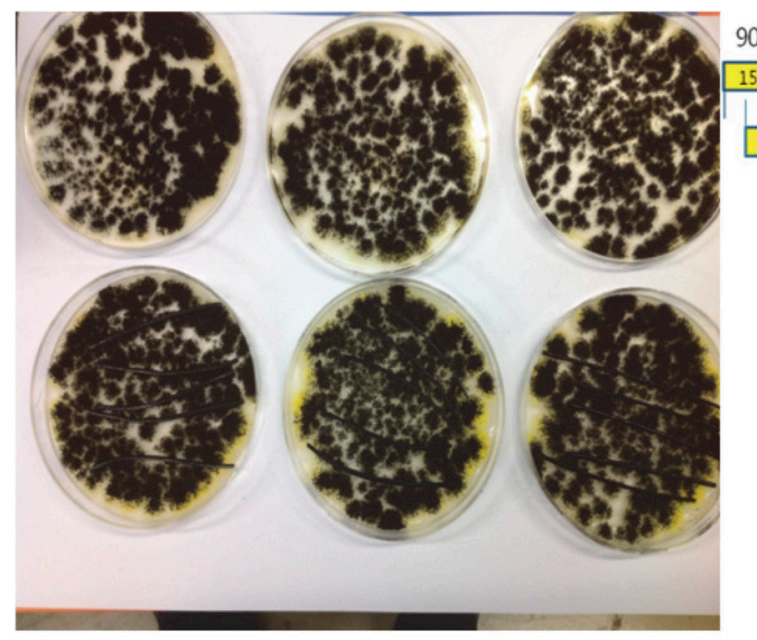

(a)

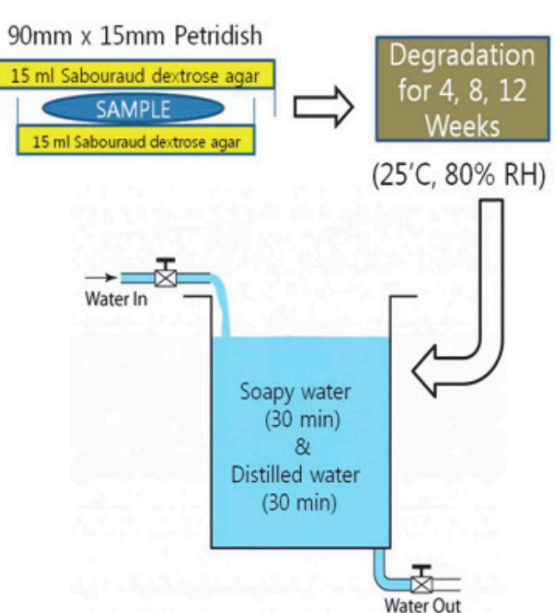

(b)

Figure 3. (a) Picture of fungi grown for $96 \mathrm{~h}$ at $25{ }^{\circ} \mathrm{C}$ and $80 \% \mathrm{RH}$ and (b) scheme of the fungal degradation test.

\subsection{Scanning Electron Microscope (SEM) Image Analysis of Degraded Blends}

The surface of the bio-degraded, modified lignin/synthetic blend was scanned by a SUPRA 55VP, Field-Emission Scanning Electron Microscope, Carl Zeiss, Germany. The degree of biodegradation was analyzed using $1000 \times$ images to show how modified lignin has an indirect effect on well-known, non-biodegradable polymers, like PET and PP.

\section{Results and Discussion}

\section{1. $31 P-N M R$}

Before quantification of modified lignin, determining a SKL functional group used in this study was necessary for this method since the lignin functional group is different according to the species of trees and/or extraction method. The position and amount of aliphatic $\mathrm{OH}(\mathrm{Al} \mathrm{OH})$ and non-condensed aromatic $\mathrm{OH}(\mathrm{NC} \mathrm{Ar} \mathrm{OH})$ were determined to be $2.4 \mathrm{mmol} / \mathrm{g}$ and $2.2 \mathrm{mmol} / \mathrm{g}$, respectively, from Hassan et al [12]. Furthermore, the main reaction sites of THFL, $\beta-\mathrm{O}-4$ alpha hydroxyl group $(\beta-\mathrm{O}-4 \mathrm{OH})$ and $\mathrm{COOH}$, were determined to be $2 \mathrm{mmol} / \mathrm{g}$ and $0.22 \mathrm{mmol} / \mathrm{g}$, respectively, by several studies [13-15]. The homopolymer of polymerized reagent of butyrolactone is P4HB (poly-4-hydroxybutyrate) and polymerized tetrahydrofuran is poly tetramethylene glycol (PTMEG). 
BLL was mainly reacted with $\mathrm{Al} \mathrm{OH}$ and $\mathrm{NC}$ Ar OH. A small amount of $\beta-\mathrm{O}-4 \mathrm{OH}$ was reacted, although $\mathrm{COOH}$ did not react in BLL modification (Figure 4). Furthermore, NC Ar OH was reacted at the initial modification stage, and a decrease in $\mathrm{Al} \mathrm{OH}$ was from chasing a $\mathrm{NC} \mathrm{ArOH}$. The new aliphatic $\mathrm{Al} \mathrm{OH}$, in other words, increased the hydroxyl group at the end of the P4HB gradually. For BLL, the carboxyl group at the end of the $\mathrm{P} 4 \mathrm{HB}$ chain that oligomerized the ring opening polymerization was reacted with the lignin hydroxyl group by trans-esterification, which is where another lignin hydroxyl group reacted with another $\mathrm{P} 4 \mathrm{HB}$ oligomer.

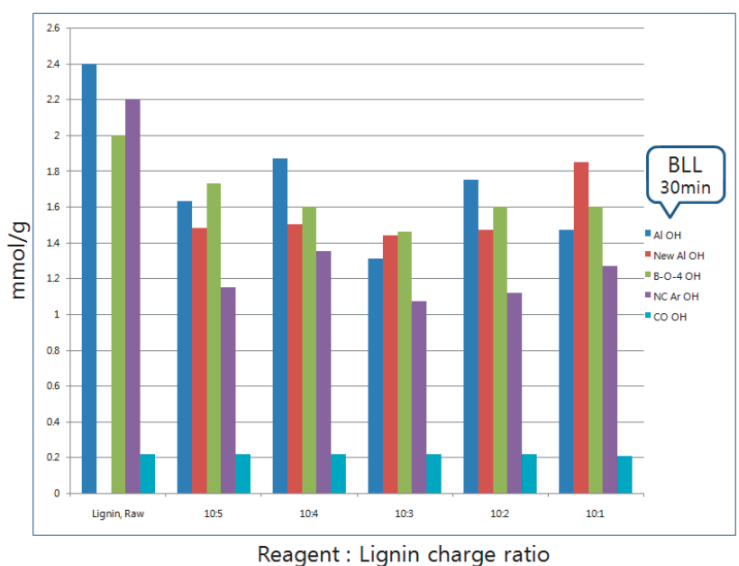

(a)

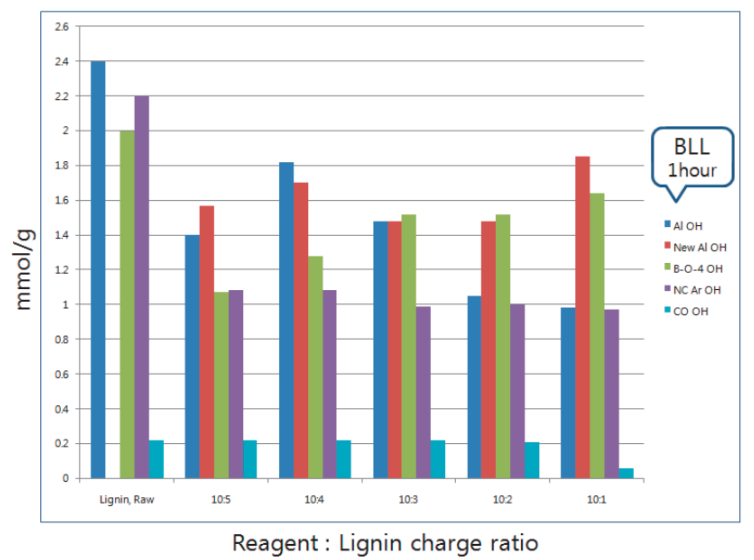

(b)

Figure 4. Changes of BLL functional groups according to the reaction charge ratio and reaction time.

By contrast, in the case of THFL, almost all $\mathrm{COOH}$ and $\beta-\mathrm{O}-4 \mathrm{OH}$ were decreased. THFL did not react to $\mathrm{Al} \mathrm{OH}$ and $\mathrm{NC} \mathrm{Ar} \mathrm{OH}$ except when the reagent charge ratio was high. In Figure 5, new $\mathrm{Al} \mathrm{OH}$ of THFL and $\mathrm{OH}$ at the end of the PTMEG were rarely present in THFL for $30 \mathrm{~min}$. It is increased when the THFL sample reacted for one hour. This is because the hydroxyl group of oligomerized PTMEG was reacted with $\mathrm{COOH}$ and $\beta-\mathrm{O}-4 \mathrm{OH}$ rapidly at the initial modification stage until, gradually, lignin-PTMEG copolymerization maximized. The specific reaction between THFL and $\beta-\mathrm{O}-4 \mathrm{OH}$ is explained in the several references [16-21]. The COOH of lignin are reacted with OH of PTMEG by trans-esterification like in BLL. COOH is a well-known, highly-reactive functional group with electron delocalization, so the OH of PTMEG is reacted first to COOH. Then, as with BLL, the copolymer of lignin-PTMEG was gradually developed (Figure 6) [22-26].

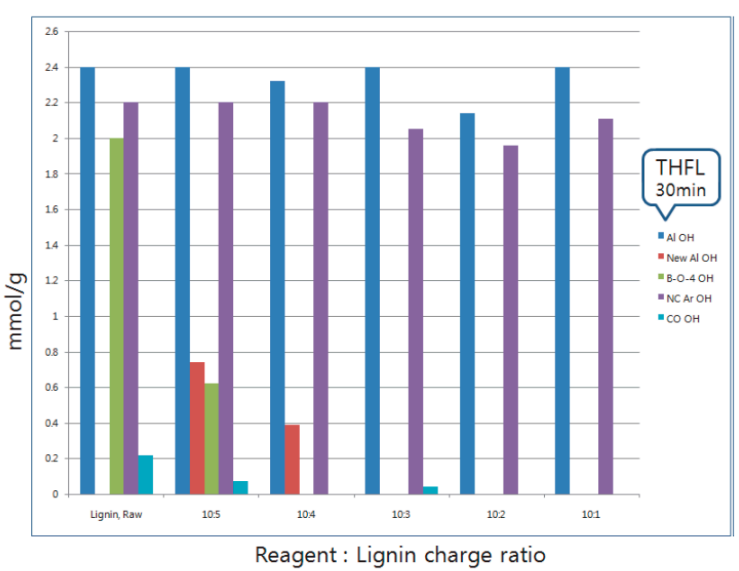

(a)

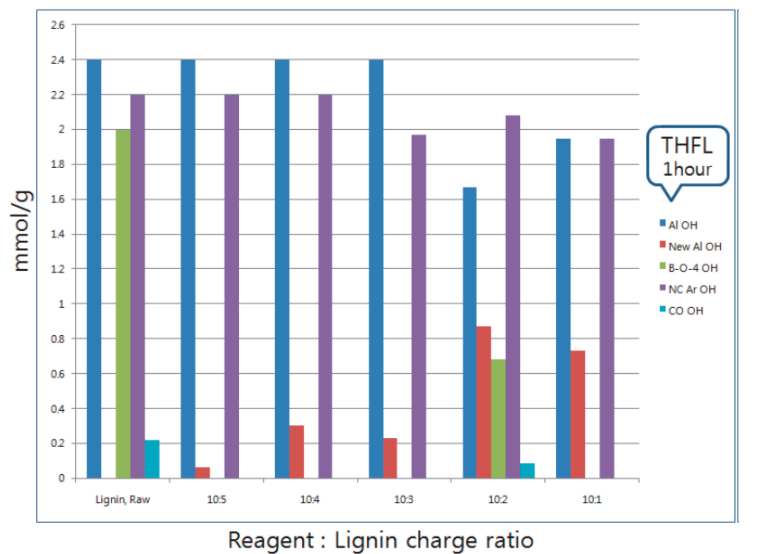

(b)

Figure 5. Changes of THFL functional groups according to the reaction charge ratio and reaction time. 


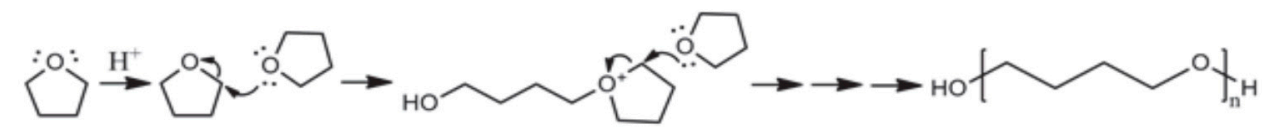

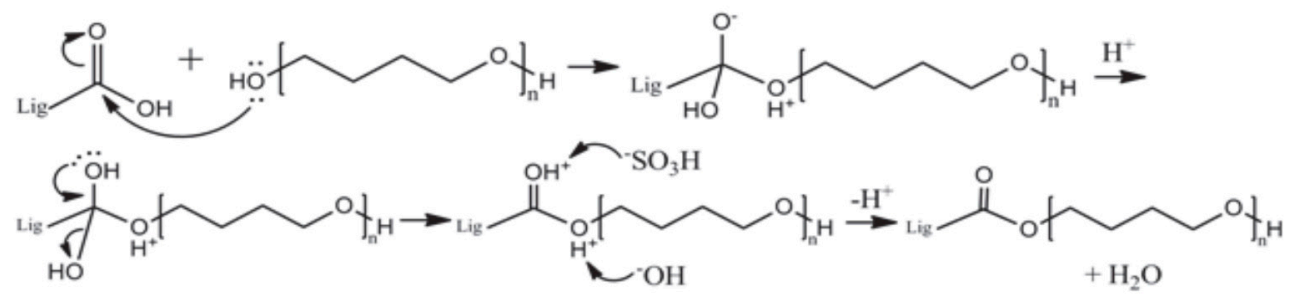

Figure 6. Reaction mechanism of modified lignin using an acid catalyst [22-26].

\subsection{FT-IR Spectra of Modified Lignin}

The intramolecular $\mathrm{OH}$ bond peak is the distinguishing feature of modified lignin observed near $3650 \mathrm{~cm}^{-1}$. (Figure 7) This is rarely observed in lignin, unlike in materials like vanillin and/or cyclohexane. In lignin, it is the evidence of degraded intramolecular hydrogen bond by lignin-aliphatic chain copolymerization.

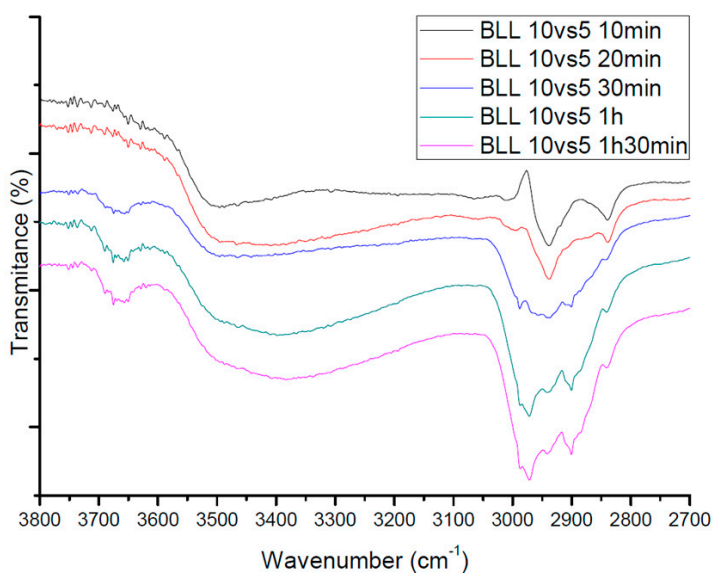

(a)

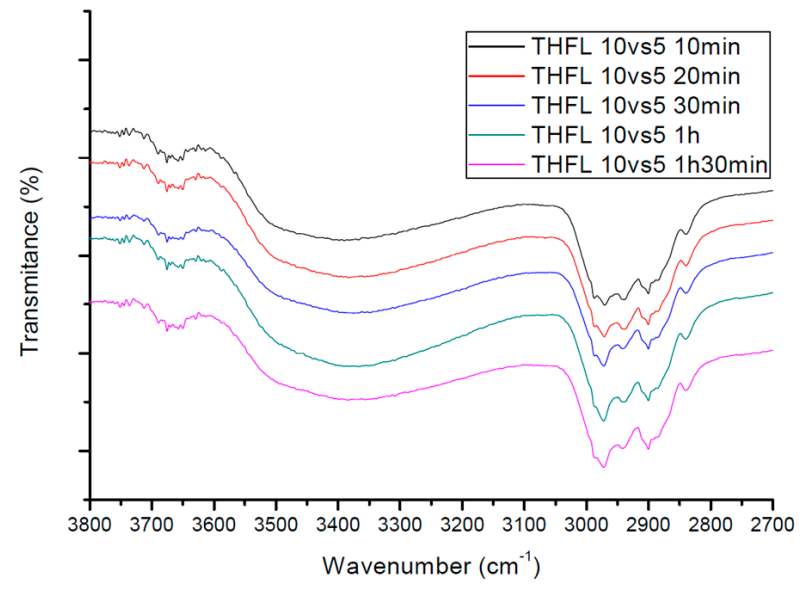

(b)

Figure 7. FT-IR spectra of (a) BLL and (b) THFL according to the reaction time.

In addition, an asymmetric stretch increases near $3000 \mathrm{~cm}^{-1} \sim 2900 \mathrm{~cm}^{-1}$ and features low molecular aromatic materials that look like lignin, according to the copolymerization of the lignin-aliphatic chain in progress. This peak is as shown as hydroxyalkylated lignin [27]. Carolina et al. studied the oxypropylation of lignin to use for polyols. Evidence of oxypropylation was checked by FT-IR analysis. Several features indicated the occurrence of propylene oxide grafting on lignin: an increase in the bands at $2971 \mathrm{~cm}^{-1} \sim 2870 \mathrm{~cm}^{-1}$ attributed to the asymmetric stretching of $\mathrm{CH}_{3}, \mathrm{CH}_{2}$, and $\mathrm{CH}$ in aromatic groups [27]. Making a connection between these two peaks, delocalized electron induced by carbonyl groups in the lignin-aliphatic chain increases the intramolecular hydrogen bond stretch, as opposed to the asymmetric stretch increasing the electron cloud in the copolymer aromatic ring captivated by electron delocalization.

\subsection{Quantification of the Insoluble Fraction in THF}

In order to quantify the modification of lignin, the insoluble fraction of modified lignin was quantified using the lignin insoluble solvent. The soluble property of lignin is insoluble in THF, the functional group of lignin had been substituted with a polymer chain that was used in the modification as shown in the various analyses, making the modified lignin soluble in the THF. The molecular 
structure of lignin was changed by modification, making the modified lignin more hydrophobic. The reason for lignin insolubility in THF, which is a hydrophobic organic solvent is due to the miscibility gap between lignin and THF by the excessive amount of hydroxyl groups of lignin. Table 1 shows the differences of insoluble fraction according to the reaction charge ratio and time. The same amount of unmodified lignin $(2 \%(v / w))$ has a 97\% 98\% insoluble fraction in the THF and this indicates the complete insolubility of lignin, considering the measuring error. However, BLL rarely shows an insoluble fraction, except for a 10:1 charge ratio. This phenomenon is due to the substituted chain that is used in the BLL modification is PHB, which has a solubility parameter (SP) value of 19.9, nearly closed SP value of THF (19.4) [28]. In the case of THFL, time variation rarely affected the differences of insoluble fraction while charge ratio was affected thoroughly. Furthermore, the insoluble fraction was increased in all charge ratios according to the time progression (30 min-1 h), because of the PTMEG chain that is used in the THFL-modified lignin had a more hydrophobic SP value than THF. It is said that PTMEG with $1000 \mathrm{Mn}$ has a high hydrophobic SP value (17) [29].

Table 1. Insoluble fraction of modified lignin in THF according to the reaction charge ratio and reaction time variation.

\begin{tabular}{cccccc}
\hline Sample Label (wt \%) & $\mathbf{1 0 : 1}$ & $\mathbf{1 0 : 2}$ & $\mathbf{1 0 : 3}$ & $\mathbf{1 0 : 4}$ & $\mathbf{1 0 : 5}$ \\
\hline BLL 30 min & 23.2 & 3.4 & 3.2 & 4 & 3.1 \\
BLL 1 h & 34.1 & 3.3 & 6.4 & 4.6 & 3.5 \\
THFL 30 min & 49.7 & 30.9 & 19.7 & 16.6 & 15.2 \\
THFL 1 h & 63.8 & 31.7 & 27.7 & 28.1 & 19.6 \\
\hline
\end{tabular}

As shown in the NMR analysis, degradation of the $\beta-\mathrm{O}-4$ linkage occurred in the initial stage of the THFL modification process and substitution of PTMEG occurred at the same time. It is inferred that degraded lignin is alongside the substituted PTMEG chain. After that, the proportion of the PTMEG chain increased according to the time progression, and the insoluble fraction of THFL had increased linearly (Table 2). Furthermore, the lignin molecular structure was changed thoroughly from the structural point of view and the functional group of THFL is rarely different from lignin because THFL did not decrease the hydroxyl group of lignin compared with BLL, as supported by the FT-IR results. From these results, lignin was modified with the well-used modification method which was proposed in this study, and this can be inferred that BLL and THFL were modified into a similar structure, while the modification sites were different.

Table 2. Insoluble fraction of modified lignin in THF according to the reaction time variation.

\begin{tabular}{cccccc}
\hline Sample Label (wt \%) & $\mathbf{1 0}$ min & $\mathbf{2 0} \mathbf{~ m i n}$ & $\mathbf{3 0} \mathbf{~ m i n}$ & $\mathbf{1} \mathbf{h}$ & $\mathbf{1} \mathbf{h} \mathbf{3 0} \mathbf{~ m i n}$ \\
\hline BLL 10:5 & 0.3 & 0.2 & 3.1 & 3.5 & 5 \\
THFL 10:5 & 14.2 & 12 & 15.2 & 19.6 & 20.9 \\
\hline
\end{tabular}

Raw lignin is completely insoluble in THF.

\subsection{Elemental Analysis of 2 h-Reacted Lignin}

In this section, the proportion of lignin in a modified lignin was analyzed by the proportion of nitrogen originated from lignin (Table 3). Considering the empirical formula of raw materials, the empirical formula of lignin is $\mathrm{C}_{9} \mathrm{H}_{6.95} \mathrm{O}_{1.05} \mathrm{~N}_{0.1} \mathrm{~S}_{0.06}(\mathrm{OCH})_{0.83}$ However, the repeat unit of modification reagent is a $\mathrm{BLL}-\mathrm{C}_{4} \mathrm{H}_{6} \mathrm{O}_{2}, \mathrm{THFL}-\mathrm{C}_{4} \mathrm{H}_{8} \mathrm{O}$. It can be easy to think that a low proportion of lignin means high aliphatic chain content, but it has low carbon and high oxygen content. 
Table 3. Nitrogen components of modified lignin according to the reaction charge ratio.

\begin{tabular}{ccccccc}
\hline Sample Label (wt \%) & $\mathbf{1 0 : 1}$ & $\mathbf{1 0 : 2}$ & $\mathbf{1 0 : 3}$ & $\mathbf{1 0 : 4}$ & $\mathbf{1 0 : 5}$ & $\mathbf{1 0 : 6}$ \\
\hline BLL & 1.176 & 1.157 & 1.233 & 1.246 & 0.819 & 0.854 \\
THFL & 1.253 & 1.113 & 1.164 & 1.098 & 1.037 & 1.04 \\
\hline
\end{tabular}

Raw lignin have a $1.2634 \mathrm{wt} \%$ of nitrogen.

For modified lignin for a ratio of 10:2 10:4, the aliphatic chain plays the role as the chain extender between lignins, as inferred from elemental analysis data. However, as shown in Figure 8, the proportion of aliphatic chains did not show linear changes and is gradually decreased as the charge ratio of lignin increased. The reason for this behavior can be explained by several studies of wood liquefaction. [30-32] The results of wood liquefaction showed that polycondensation took place when the charge ratios were 2 and 4, while polycondensation was not observed under the larger charge ratios, such as 6 and 10. The residue of liquefied wood is insoluble in DMF, which had resulted in the polycondensation [33]. From these results, degradation of lignin mainly occurred in the initial stage of modification, polycondensation occurred according to the time progress, and molecular weight increased rapidly at the end of the modification process. Furthermore, polycondensation occurrence needs a proper reaction condition, such as charge ratio, reaction time, catalyst ratio and type of raw materials. From these results, a $2 \mathrm{~h}$ reacted sample with a ratio of 10:6 is appropriate for the basic purposes of this study because of the low unreacted reagent and high lignin modification yield. A fixed condition of reacted lignin was used in the modified lignin/polymer blend section.

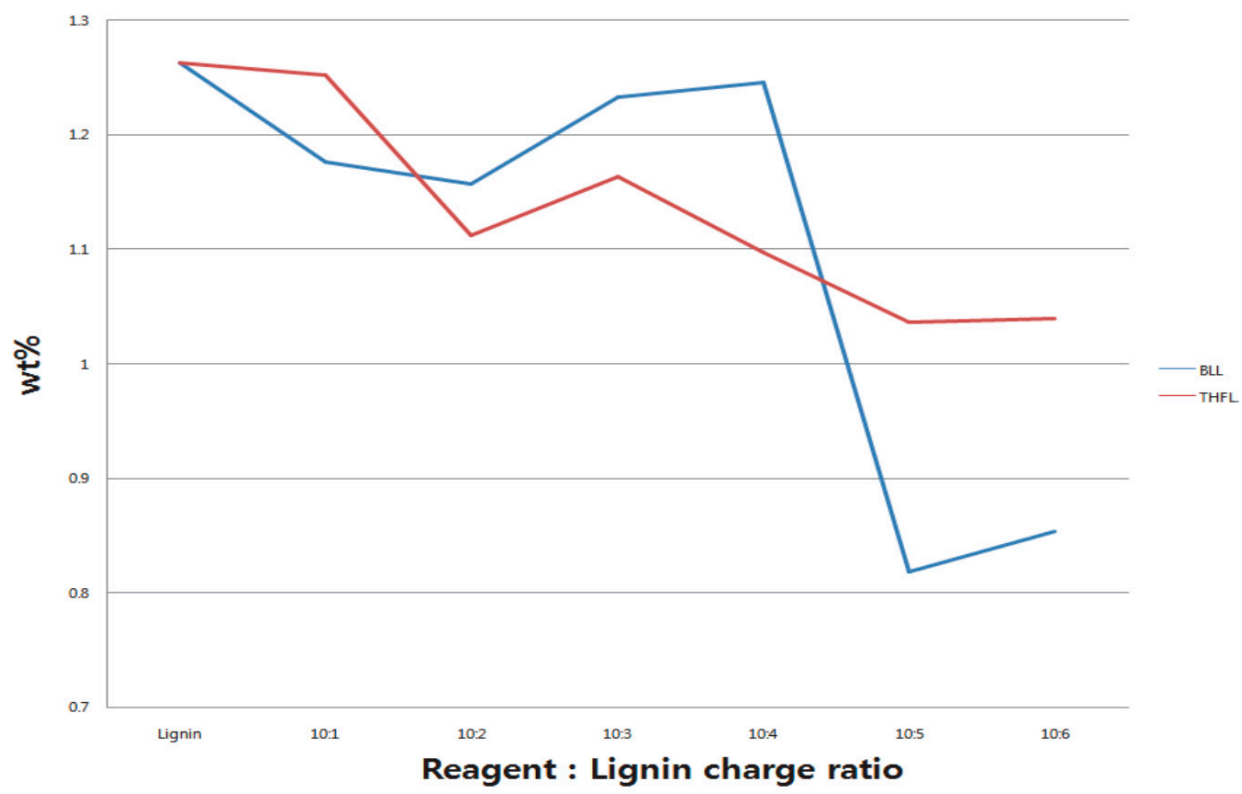

Figure 8. Decrease of nitrogen contents of modified lignin according to the reaction charge ratio.

\subsection{XRD Analysis of Modified Lignin/Polymer Blends}

The blend of BLL/PET showed an increase in crystallinity more than PET only, and the reduction of crystallinity in the THFL/PP blend was rarely decreased. The THFL/PP blend showed a gradual decrease in crystallinity, whereas the crystallinity of the BLL/PET blend increased gradually because THFL acted as a filler (Table 4). However, the increase in crystallinity of PET due to the BLL addition is strong evidence for the good compatibility between BLL and PET. 
Table 4. Degree of crystallinity of PP/THFL and PET/BLL blends [34].

\begin{tabular}{ccccc}
\hline Blend Type \& Proportion (\%) & $\mathbf{1 0 0 : 0}$ & $\mathbf{7 5 : 2 5}$ & $\mathbf{5 0 : 5 0}$ & $\mathbf{0 : 1 0 0}$ \\
\hline PP/THFL & 51.7 & 49.5 & 40 & 3.3 \\
PET/BLL & 30.1 & 35.4 & 33.4 & 10.9 \\
\hline
\end{tabular}

Furthermore, the crystal structure change of PET by the addition of BLL, as shown in Figure 9, means that molecular chain of BLL and PET are enough to compatibly entangle with each other. Additionally, it indicates the high compatibility of the PET/BLL blend along with increasing of the degree of crystallinity and peak shift of Tg in the DSC analysis. However, the PP/THFL blend did not show a dramatic change like the PET/BLL blend.

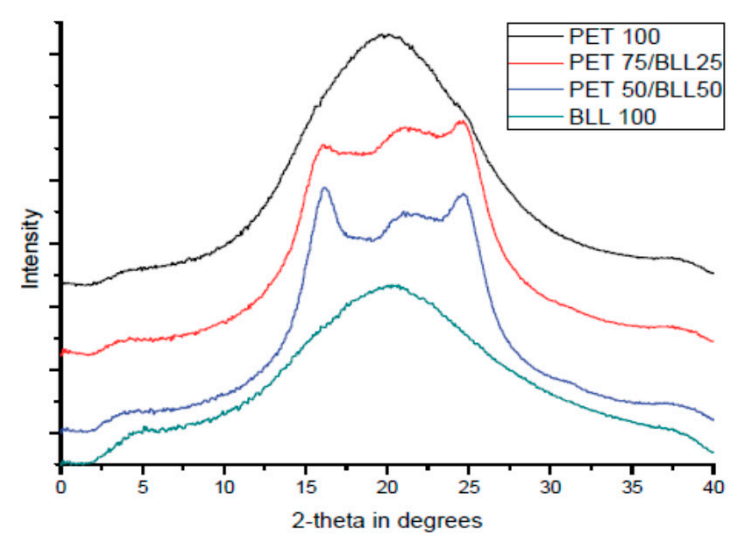

(a)

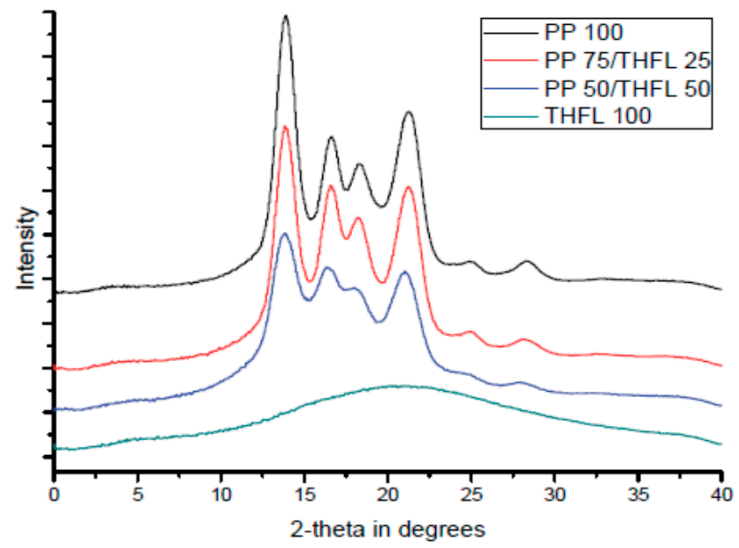

(b)

Figure 9. Changes of the crystal structure according to the (a) BLL and (b) THFL contents.

\subsection{Tensile Test of $2 \mathrm{~h}$-Modified Lignin and Polymer Blends}

All of the mechanical properties of the PP/THFL blend were enhanced compared to lignin or the acetylated lignin/ polymer blend, which was confirmed by comparing their mechanical properties in this study, as well as other studies [35,36]. When modified lignin is incorporated into a PP matrix, the overall physical properties of the resulting composite are improved, such as when clay or talc is integrated into a general PP composite. Table 5 shows that the tensile properties of the PP/THFL blended matrix slightly decreased with the THFL content compared to the PP/lignin blend [5-7]. There was no significant change in the tensile strength, although the tensile strength of the matrix containing 50\% THFL was slightly lower than that of the matrix containing 25\% THFL. On the other hand, the tensile strength of the PET/BLL blend decreased as BLL content increased because P4HB is highly elastic and, thus, had a low modulus of $70 \mathrm{MPa}$ [37]. In the case of the PET/BLL blend, the stress-strain seemed to follow the rule of mixture. Young's modulus values decreased with the increase of BLL content from $1145 \mathrm{MPa}$ to $126 \mathrm{MPa}$. However, elongation increased significantly with the increased concentration of BLL while the tensile strength decreased with the decreased concentration of PET. This result was attributed to the fact that P4HB exhibits $1000 \%$ elongation [38]. Since the mechanical properties of the polymer mixture follow the "rule of mixture", the mechanical properties of the PET/BLL blend seemed to exhibit a mechanical performance proportional to the BLL content. These results indicate that the material used to modify lignin retains its material properties and affects the mechanical properties of the final blend due to the decreased number of $\mathrm{OH}$ bonds in lignin. Furthermore, the aliphatic chains that replaced the $\mathrm{OH}$ groups of lignin were confirmed to reduce the brittleness of lignin. 
Table 5. Tensile properties of polymer/modified lignin blends [34].

\begin{tabular}{cccc}
\hline $\begin{array}{c}\text { Blend Type \& } \\
\text { Proportion (\%) }\end{array}$ & $\begin{array}{c}\text { Ultimate Tensile } \\
\text { Strength (MPa) }\end{array}$ & $\begin{array}{c}\text { Young's } \\
\text { Modulus (MPa) }\end{array}$ & $\begin{array}{c}\text { Elongation at } \\
\text { Break (\%) }\end{array}$ \\
\hline PP 100 & $32.42( \pm 2.2)$ & $711( \pm 143)$ & $4.39( \pm 0.42)$ \\
PP75/THFL25 & $26.37( \pm 3.8)$ & $712( \pm 192)$ & $8.57( \pm 0.83)$ \\
PP50/THFL50 & $24.73( \pm 0.9)$ & $959( \pm 154)$ & $9.56( \pm 1.25)$ \\
\hline PET 100 & $45.49( \pm 4.4)$ & $1145( \pm 203)$ & $5.33( \pm 0.02)$ \\
PET75/BLL25 & $23.23( \pm 2.7)$ & $601( \pm 57)$ & $447( \pm 72)$ \\
PET50/BLL50 & $7.26( \pm 1.3)$ & $126( \pm 8)$ & $503( \pm 87)$ \\
\hline
\end{tabular}

\subsection{Degradation Behavior of PP/THFL and PET/BLL}

Table 6 shows the results of mechanical test and weight loss after degradation. There was no significant weight loss in the 12-week experiment [39]. However, there was an obvious decrease of strain in all of the samples. In the case of the PP/THFL blends, a small change in tensile strength, decrease in strain, and increase in modulus was observed. It seems that a small change has occurred in the PP/THFL blend material during the degradation test because the THFL and PP were separated in the blend.

Table 6. Tensile properties and weight change of polymer/modified lignin-75/25 blends degraded by fungus [34].

\begin{tabular}{ccccc}
\hline $\begin{array}{c}\text { Degradation } \\
\text { Time (Week) }\end{array}$ & $\begin{array}{c}\text { Ultimate Tensile } \\
\text { Strength (MPa) }\end{array}$ & $\begin{array}{c}\text { Elongation at } \\
\text { Break (\%) }\end{array}$ & $\begin{array}{c}\text { Young's } \\
\text { Modulus (MPa) }\end{array}$ & $\begin{array}{c}\text { Weight } \\
\text { Loss (\%) }\end{array}$ \\
\hline PP/THFL 4W & $19.7( \pm 1.6)$ & $8.8( \pm 1.57)$ & $634.8( \pm 239)$ & 2 \\
PP/THFL 8W & $22.8( \pm 3.1)$ & $5.6( \pm 0.77)$ & $1031( \pm 173)$ & 2 \\
PP/THFL 12W & $24.8( \pm 0.8)$ & $5.5( \pm 0.21)$ & $1264( \pm 175)$ & +1.3 \\
\hline PET/BLL 4W & $12.1( \pm 2.1)$ & $6.3( \pm 0.14)$ & $1524( \pm 320)$ & 1 \\
PET/BLL 8W & $9.8( \pm 0.6)$ & $2( \pm 0.56)$ & $1347( \pm 341)$ & 0.5 \\
PET/BLL 12W & $9( \pm 0.4)$ & $1.8( \pm 0.04)$ & $1408( \pm 149)$ & +1.5 \\
\hline
\end{tabular}

However, in the case of the PET/BLL blend, the tensile strength and strain decreased dramatically and the modulus increased more than double than that before degradation. This is because the chain degradation makes materials 'brittle', as shown in the bulk erosion process or photo-degradation of polymers [40,41]. The PET/BLL blend had a similar weight loss as it was shown in the PP/THFL blend. However, the PET/BLL blend showed good compatibility, which means that a chain of P4HB and PET is in a single phase lamella structure. After active biodegradation occurred, the lamella structure of the blend was weakened [42].

Furthermore, Figures 10 and 11 show $1000 \times$ degraded SEM images of modified lignin/PP and PET, which are well known non-degradable plastics. It can be shown that degradation occurred and increased as the time progresses, while the zero-week sample had shown smooth surfaces. If antioxidant was not added, lignin and substituted aliphatic chain degradation occurred with oxidative degradation not only of itself but also of the matrix polymer, as shown in a study of degradation behavior of lignin-blended PE and PP in a fungal degradation environment [43]. In the case of 12-week samples of the PET/BLL blend, it shows that the after-degraded product can be observed on the surface of a sample, while the PP/THFL blend degraded sample only shows burrowed defects into the surface. This means more active degradation occurred in the PET/BLL blend and it can be also confirmed by more decreased mechanical properties of the PET/BLL blend because P4HB is a well-known degradable polymer which can be used as a scaffold [37]. 

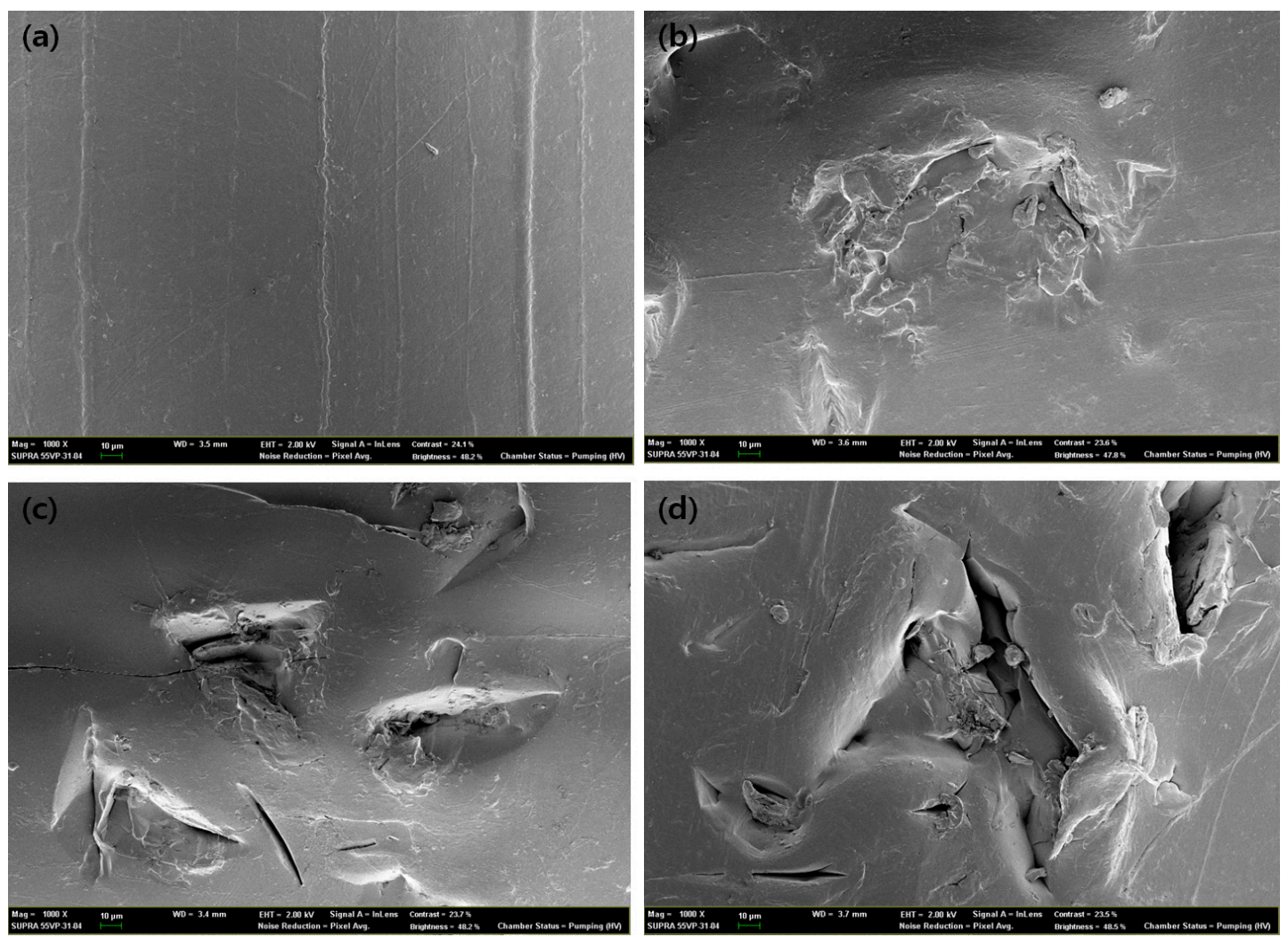

Figure 10. SEM pictures at the magnification of $1000 \times$ of PP/THFL $75 / 25$ blend after degradation, (a) zero weeks; (b) four weeks; (c) eight weeks; and (d) 12 weeks.
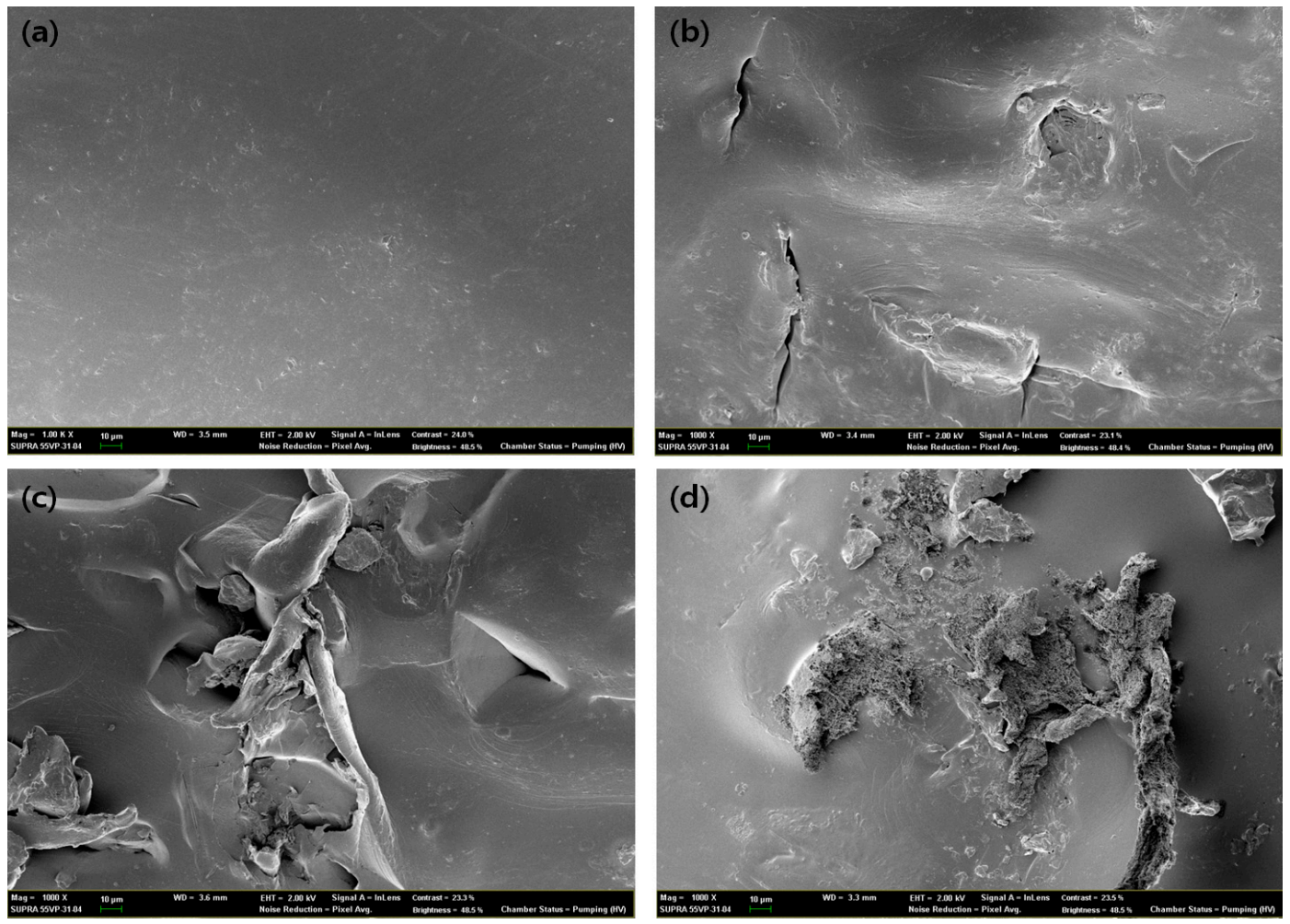

Figure 11. SEM pictures at the magnification of $1000 \times$ of PET/BLL 75/25 blend after degradation, (a) zero weeks; (b) four weeks; (c) eight weeks; and (d) 12 weeks. 


\section{Summary and Conclusions}

The purpose of this study was to propose an easy and inexpensive method of the modification of lignin. Various analyses were performed using different types of reagents to modify lignin. The reagents were used to mimic the LCC structure. The reaction site of modification was different with respect to the reagent, according to the results of 31P-NMR analysis. BLL was mainly reacted with $\mathrm{Al} \mathrm{OH}$ and $\mathrm{NC}$ Ar OH. A small amount of $\beta-\mathrm{O}-4 \mathrm{OH}$ was reacted. THFL did not react with $\mathrm{AlOH}$ and $\mathrm{NC} \mathrm{Ar} \mathrm{OH}$, but reacted with $\mathrm{COOH}$ and $\beta-\mathrm{O}-4 \mathrm{OH}$ rapidly at the initial modification stage. This is because of the low polarity of THF. $\beta$-O-4 linkage of lignin was degraded rapidly at the initial stage of modification, PTMEG substitution occurred at the same time. Polycondensation occurred in the last stage of modification. The yield of modification was higher when the charge ratio of lignin and the reaction time were higher.

XRD results showed the degree of crystallinity of the blend and interactions were different due to the types of the modified lignins and polymers. Tensile results indicate that the material used to modify lignin retains its material properties and affects the mechanical properties of the final blends, probably due to the decreased number of $\mathrm{OH}$ bonds in the lignin. In order to show the degradation behavior by addition of BLL and THFL, degradation test was performed for 12 weeks with four-week intervals. It was found that blends using BLL and THFL were degraded. BLL shows more active degradation. From this study, a new method of lignin modification is proposed, and it is found that modified lignin will retain the property of substituted aliphatic chains. This method could be a proper lignin modification method.

Acknowledgments: This research was supported by the Basic Science Research Program through the National Research Foundation of Korea, funded by the Ministry of Education, Science and Technology, Republic of Korea (No. 20110015593), "Development of High Stiffness and Thermal Resistant Materials for High Performance Automotive Lighting System" funded by KOPRA Co., Ltd., Fundamental R\&D Program for Technology of Materials \& Components (No. 10050526) funded by the Ministry of Trade, Industry and Energy, Republic of Korea and the Research Institute of Agriculture and Life Sciences at Seoul National University.

Author Contributions: Sunghoon Kim, Seungtaek Oh, and Jongshin Park conceived and designed the experiments. Sunghoon Kim performed the experiments and wrote this paper. Sunghoon Kim and Jongshin Park analyzed the data. Jungmin Lee and Hyun-gyoo Roh helped the data anlaysis and the discussions.

Conflicts of Interest: The authors declare no conflict of interest.

\section{References}

1. Van de Ven, T.; Louis, G. Agricultural and Biological Sciences Cellulose Fundamental Aspects; InTech Books: Rijeka, Croatia, 2013; pp. 250-260.

2. Kubo, S.; Gilbert, R.D.; Kadla, J.F. Natural Fibers, Biopolymers, and Biocomposites; Mohanty, A.K., Misra, M., Drzal, L.T., Eds.; Taylor and Francis: Boca Raton, FL, USA, 2005; p. 674.

3. Li, H.; McDonald, A.G. Fractionation and characterization of industrial lignins. Ind. Crops Prod. 2014, 62, 67-68.

4. Feldman, D. Lignin and its Polyblends-A Review. In Chemical Modification, Properties, and Usage of Lignin; Thomas, Q., Ed.; Kluwer Academic/Plenum Publishers: New York, NY, USA, 2002; pp. 81-82.

5. Alexya, P.; Kosikova, B.; Podstranska, G. The effect of blending lignin with polyethylene and polypropylene on physical properties. Polymer 2000, 41, 4901-4908.

6. Sanchez, C.G.; Alvarez, L.A.E. Micromechanics of lignin/polypropylene composites suitable for industrial applications. Angew. Makromol. Chem. 1999, 272, 65-70. [CrossRef]

7. Barzegari, M.R.; Alemdar, A.; Zhang, Y.; Rodrigue, D. Mechanical and Rheological Behavior of Highly Filled Polystyrene with Lignin. Polym. Compos. 2012, 33, 353-361. [CrossRef]

8. Li, J.; He, Y.; Inoue, Y. Thermal and mechanical properties of biodegradable blends of poly(L-lactic acid) and lignin. Polym. Int. 2003, 52, 949-955. [CrossRef]

9. Fengel, D.; Przyklenk, M. Studies on Alkali Extract from Beech Holocellulose. Wood Sci. Technol. 1976, 10, 311-320. 
10. Alexander, L. X-ray Diffraction Methods in Polymer Science; Wiley Interscience: New York, NY, USA, 1969; pp. 165-172.

11. Difco ${ }^{\mathrm{TM}} \mathcal{E} B B L^{\mathrm{TM}}$ Manual, 2nd ed.; Becton, Dickinson and Company: Sparks Glencoe, MD, USA, 2009.

12. Sadeghifar, H.; Cui, C.; Argyropoulos, D.S. Toward Thermoplastic Lignin Polymers. Part 1. Selective Masking of Phenolic Hydroxyl Groups in Kraft Lignins via Methylation and Oxypropylation Chemistries. Ind. Eng. Chem. Res. 2012, 51, 16713-16720. [CrossRef]

13. Argyropoulos, D.S. Quantitative Phosphorus-31 NMR Analysis of Lignins, a New Tool for the Lignin Chemist. J. Wood Chem. Technol. 1994, 14, 45-63. [CrossRef]

14. Cui, C.; Sadeghifar, H.; Sen, S.; Argyropoulos, D.S. Toward Thermoplastic Lignin Polymers; Part 2: Thermal \& Polymer Characteristics of kraft Lignin \& Derivatives. Bioresources 2013, 8, 864-886.

15. Balakshin, M.; Capanema, E. On the Quantification of Lignin Hydroxyl Groups with 31P and 13C-NMR Spectroscopy. J. Wood Chem. Technol. 2015, 35, 220-237. [CrossRef]

16. Lin, L.Z.; Yao, Y.G.; Yoshioka, M.; Shiraishi, N. Liquefaction mechanism of lignin in the presence of phenol at elevated temperature without catalysts: Studies on $\beta-\mathrm{O}-4$ lignin model compound. 1 . Structural characterization of the reaction products. Holzforschung 1997, 51, 316-324. [CrossRef]

17. Lin, L.Z.; Yao, Y.G.; Yoshioka, M.; Shiraishi, N. Liquefaction mechanism of lignin in the presence of phenol at elevated temperature without catalysts: Studies on $\beta-\mathrm{O}-4$ lignin model compound. 2. Reaction pathway. Holzforschung 1997, 51, 325-332. [CrossRef]

18. Lin, L.Z.; Yao, Y.G.; Yoshioka, M.; Shiraishi, N. Liquefaction mechanism of lignin in the presence of phenol at elevated temperature without catalysts: Studies on $\beta-\mathrm{O}-4$ lignin model compound. 3. Multi condensation. Holzforschung 1997, 51, 333-337. [CrossRef]

19. Lin, L.Z.; Yao, Y.G.; Shiraishi, N. Liquefaction mechanism of $\beta-\mathrm{O}-4$ lignin model compound in the presence of phenol under acid catalysis. Part 1. Identification of the reaction products. Holzforschung 2001, 55, 617-624. [CrossRef]

20. Lin, L.Z.; Yao, Y.G.; Shiraishi, N. Liquefaction mechanism of $\beta-\mathrm{O}-4$ lignin model compound in the presence of phenol under acid catalysis. Part 2. Reaction behavior and pathways. Holzforschung 2001, 55, 625-630.

21. Choi, Y.S.; Singh, R.; Zhang, J.; Balasubramanian, G.; Sturgeon, M.R.; Katahira, R.; Chupka, G.; Beckham, G.T.; Shanks, B.H. Pyrolysis reaction networks for lignin model compounds: Unraveling thermal deconstruction of $\beta-\mathrm{O}-4$ and $\alpha-\mathrm{O}-4$ compounds. Green Chem. 2016, 18, 1762-1773. [CrossRef]

22. Nuyken, O.; Pask, S.D. Ring-Opening Polymerization-An Introductory Review. Polymers 2013, 5, 363-374. [CrossRef]

23. Gresham, T.L.; Jansen, J.E.; Shaver, F.W.; Propiolactone, I. Polymerization Reactions. J. Am. Chem. Soc. 1948, 70, 998-999. [CrossRef]

24. Foster, N.C. Sulfonation and Sulfation Processes; The Chemithon Corporation: Seattle, WA, USA, 1997.

25. Whitby, R.L.D.; Smith, L.C.; Dichello, G.; Fukuda, T.; Maekawa, T.; Mikhalovsky, S.V. Cationic ring-opening polymerization of lactones onto chemically modified single layer graphene oxide. Mater. Express 2014, 4, 242-244. [CrossRef]

26. Impallomeni, G.; Giuffrida, M.; Barbuzzi, T.; Musumarra, G.; Ballistreri, A. Acid Catalyzed Transesterification as a Route to Poly(3-hydroxybutyrate-co- $\varepsilon$-caprolactone) Copolymers from Their Homopolymers. Biomacromolecules 2002, 3, 837-839. [CrossRef]

27. Cateto, C.A.; Barreiro, M.F.; Rodrigues, A.E.; Belgacem, M.N. Optimization Study of Lignin Oxypropylation in View of the Preparation of Polyurethane Rigid Foams. Ind. Eng. Chem. Res. 2009, 48, 2586-2588. [CrossRef]

28. Terada, M.; Marchessault, R.H. Determination of solubility parameters for poly(3-hydroxyalkanoates). Int. J. Biol. Macromol. 1999, 25, 207-215. [CrossRef]

29. Xia, W.; Binyi, Z.; Zhengyi, L.; Yunzhao, Y. Studies on Epoxy Resins Modified with Poly(butylenes terephthalate)-b-Poly(tetramethylene glycol). Chin. J. Polym. Sci. 1997, 15, 84-91.

30. Niu, M.; Zhao, G.; Alma, M.H. Thermogravimetric studies on condensed wood residues in polyhydric alcohols liquefaction. Bioresources 2011, 6, 617.

31. Hassan, E.M.; Shukry, N. Polyhydric alcohol liquefaction of some lignocellulosic agricultural residues. Ind. Crops Prod. 2008, 27, 33-38. [CrossRef]

32. Kobayashi, M.; Asano, T.; Kajiyama, M.; Tomita, B. Analysis on residue formation during wood liquefaction with polyhydric alcohol. J. Wood Sci. 2004, 50, 408-409. [CrossRef] 
33. Zhang, Y.; Ikeda, A.; Hori, N.; Takemura, A.; Ono, H.; Yamada, T. Characterization of liquefied product from cellulose with phenol in the presence of sulfuric acid. Bioresour. Technol. 2006, 97, 315-319. [CrossRef] [PubMed]

34. Kim, S.; Park, J.; Lee, J.; Roh, H.; Jeong, D.; Cho, S.; Oh, S. Potential of a Bio-disintegrable Polymer Blend Using Alkyl-chain-modified Lignin. Fibers Polym. 2015, 16, 744-751. [CrossRef]

35. Jeong, H.; Park, J.; Kim, S.; Lee, J.; Jo, J. Use of Acetylated Softwood Kraft Lignin as Filler in Synthetic Polymers. Fibers Polym. 2012, 13, 1310. [CrossRef]

36. Koshijima, T.; Watanabe, T.; Yaku, F. Lignin: Properties and Materials; Glasser, W.G., Sarakanen, S., Eds.; ACS Symposium Series: Washington, DC, USA, 1989; pp. 15-26.

37. Martin, D.P.; Williams, S.F. Medical Applications of Poly-4-Hydroxybutyrate: A strong flexble absorbable biomaterial. Biochem. Eng. J. 2003, 16, 97-105. [CrossRef]

38. Moore, T.; Adhikari, R.; Gunatillake, P. Chemosynthesis of bioresorbable poly( $\gamma$-butyrolactone) by ring-opening polymerization-A review. Biomaterials 2005, 26, 3771-3782. [CrossRef] [PubMed]

39. Lee, W.K.; Doi, Y.; Ha, C.S. Retardation Effect of Enzymatic Degradation of Microbial Polyesters at the Surface by Blending with Polystyrene. Macromol. Biosci. 2001, 1, 114-118. [CrossRef]

40. Van Blitterswijk, C. Tissue Engineering; Academic Press: London, UK, 2008; pp. 205-206.

41. Islam, M.S.; Pickering, K.L.; Foreman, N.J. Influence of accelerated ageing on the physico-mechanical properties of alkali-treated industrial hemp fibre reinforced poly(lactic acid) (PLA) composites. Polym. Degrad. Stab. 2010, 95, 62. [CrossRef]

42. Iwata, T.; Doi, Y. Crystal structure and biodegradation of aliphatic polyester crystals. Macromol. Chem. Phys. 1999, 200, 2429-2442. [CrossRef]

43. Mikulasova, M.; Kosikova, B.; Alexy, P.; Kacik, F.; Urgelova, E. Effect of blending lignin biopolymer on the biodegradability of polyyolefin plastics. World J. Microbiol. Biotechnol. 2001, 17, 603-605. [CrossRef]

(C) 2016 by the authors; licensee MDPI, Basel, Switzerland. This article is an open access article distributed under the terms and conditions of the Creative Commons Attribution (CC-BY) license (http://creativecommons.org/licenses/by/4.0/). 